\title{
Vitamin C Supplementation Reduces Exercise-Induced Oxidative Stress and Increases Peak Muscular Force
}

\author{
Levi W. Evans, Fan Zhang, Stanley T. Omaye \\ Agriculture, Nutrition and Veterinary Sciences Department, University of Nevada, Reno, USA \\ Email: levie@nevada.unr.edu
}

How to cite this paper: Evans, L.W., Zhang, F. and Omaye, S.T. (2017) Vitamin C Supplementation Reduces Exercise-Induced Oxidative Stress and Increases Peak Muscular Force. Food and Nutrition Sciences, 8, 812-822.

https://doi.org/10.4236/fns.2017.88058

Received: July 12, 2017

Accepted: August 11, 2017

Published: August 14, 2017

Copyright (c) 2017 by authors and Scientific Research Publishing Inc. This work is licensed under the Creative Commons Attribution International License (CC BY 4.0).

http://creativecommons.org/licenses/by/4.0/

\begin{abstract}
Vitamin $\mathrm{C}$ is a popular supplement in exercise and sport for its chemical properties i.e. antioxidant capabilities. However, no clear role has been established for vitamin C supplementation (VCS) within these areas despite nearly a century's worth of ongoing research. This study examined peak muscular pushing force (PMF) before and after a VCS intervention, $250 \mathrm{mg}$ every $12 \mathrm{hrs}$ for 28 days, in nine participants whom were naive to VCS and resistance exercise (RE). A dynamometer was used to perform two RE bouts, pre- and post-intervention, that quantified PMF during a state of exercise-induced oxidative stress (EI-OS). Saliva was collected for EIOS analysis from each participant before and after each RE bout; salivary vitamin C (VC) and free salivary malondialdehyde (MDA) were the examined biomarkers. PMF increased significantly post-intervention $\left(405.48 \pm 92.75 \mathrm{~m} \cdot \mathrm{kg} \cdot \mathrm{s}^{-2}\right)$ from baseline $(368.31$ $\left.\pm 76.36 \mathrm{~m} \cdot \mathrm{kg} \cdot \mathrm{s}^{-2}, \mathrm{p}<0.05\right)$. MDA elevated significantly after the pre-intervention RE bout $(0.385 \pm 0.017 \mu \mathrm{g} / \mathrm{mL})$ and the post-intervention RE bout $(0.373$ $\pm 0.014 \mu \mathrm{g} / \mathrm{mL})$ compared to the baseline measures $(0.373 \pm 0.014 \mu \mathrm{g} / \mathrm{mL}$, $0.359 \pm 0.008 \mu \mathrm{g} / \mathrm{mL} ; \mathrm{p}<0.01)$; a significant reduction in MDA was observed post-intervention, confirming vitamin C's ability to reduce oxidative stress ( $\mathrm{p}$ $<0.05)$. VC increased post-intervention $(1.22 \pm 0.73 \mu \mathrm{g} / \mathrm{mL})$ from baseline $(0.47 \pm 0.51 \mu \mathrm{g} / \mathrm{mL}, \mathrm{p}<0.001)$. The results from this study suggest VCS is capable of increasing PMF by reducing EIOS in untrained individuals, and can be possibly used for enhancing resistance-exercise performance.
\end{abstract}

\section{Keywords}

Untrained Persons, Free Salivary Malondialdehyde, Isokinetic Exercise

\section{Introduction}

A redox reaction imbalance, in which oxidized compounds are in abundance 
compared to reducing agents, is known as oxidative stress, specifically in regards to biological systems. Oxidative stress can be detrimental to biological systems as it can be damaging on a cellular and molecular level [1]. A variety of exercises, including resistance/anaerobic exercise [2] [3], at various levels of intensities will produce reactive species and induce a state of oxidative stress [4] [5]. Reactive species interact with $\mathrm{Ca}^{2+}$ at the sarcoplasmic reticulum (SR) site of release and on the Troponin protein complex binding site; this environment's redox state plays a role in the overall outcome of the muscle contraction [6]. Oxidative stress can restrict the muscle's ability to contract and produce force [7], factors pivotal to exercise and sport performance. Reactive species and free radicals, however, play important roles in cellular processes and exercise adaptations [8]. A person whom is naive to exercise might observe negative effects [9], depending on the intensity level; adaptation to the activity and EIOS, however, might allow for beneficial outcomes as the person becomes more experienced and exposed to the exercise.

Reducing agents, also known as antioxidants, are available either by endogenous production (such as superoxide dismutase, glutathione peroxidase, and catalase) or by exogenous food/supplement consumption (such as vitamin $\mathrm{C}$ and vitamin $\mathrm{E}$ ). Vitamin $\mathrm{C}$ is an essential nutrient for humans, and other animals, that acts as a cofactor, a co-substrate, and as an antioxidant [10]. It is involved in hydroxylation reactions for the synthesis of cartilage, cortisol, and epinephrine; tyrosine and fatty acid metabolism require vitamin $\mathrm{C}$, as well. It is capable of recycling oxidized antioxidants, such as vitamin $\mathrm{E}$, and reducing oxidative stress. Active locations of vitamin $\mathrm{C}$ can be found throughout the body's tissues; these include the lungs, adrenal glands, plasma, leukocytes, and saliva [11]. Foods containing vitamin $\mathrm{C}$ include peppers, kale, and strawberries. Supplemental doses greater than $500 \mathrm{mg}$ of vitamin C per day will mostly be excreted [12]; smaller doses spread throughout the day will fully saturate the body and maximize its bioavailability, this technique was implemented in the present study.

Antioxidants may be beneficial in physical exercise with their ability to reduce reactive species, theoretically countering the detriments of oxidative stress e.g. muscular force inhibition and fatigue. This has led to a trend of antioxidant supplementation, with vitamin C being one of the more popular choices [13] [14]. Vitamin C's role in sport and exercise was examined as early as the 1930's [15] [16] and has since been a spotlight. VCS can reduce EIOS [17] [18]; however, evidence confirming this as beneficial [18] [19], detrimental [20], or indifferent [21] is unclear due to confounding results. The variance amongst study methods and instrumentation may be reasons for the overall inconclusiveness. Despite this, VCS is still commonly implemented in sport and exercise nutrition.

VCS has been historically restricted to studies focused on aerobic exercise as it can be actively located in the lungs, theoretically reducing free radicals produced from increased electron transport chain activity. Research examining VCS in RE is limited compared to research in aerobic exercise. A reduction in muscle soreness induced via RE has been witnessed after acute VCS at $3 \mathrm{~g} / \mathrm{day}$ and $400 \mathrm{mg} /$ 
day [17] [18]. VCS has also had no effect on RE-induced muscle soreness [22]. $\mathrm{RE}$ performance is often assessed via strength and force; common methods for this assessment are maximal weight achieved via free weight exercises and muscular force measured via dynamometry [23]. VCS has had no effect on [17] and has inhibited [22] such RE performance measures at doses of $3 \mathrm{~g}$ and $1 \mathrm{~g} / \mathrm{day}$, respectively.

Both antioxidants as well as reactive species, and their products, should be assessed when monitoring oxidative stress [8]. Salivary analysis has been proposed for EOIS assessment [24] and has since been used successfully [25]. Relevant biomarkers that can be found in saliva are lipid peroxidation products, such as thiobarbituric acid reactive substances (TBARS) and MDA, as well as vitamin C. Methods and instrumentation are important factors when using saliva, as it has been unsuccessful at observing EIOS that was otherwise present in plasma [2]. The reason behind these confounding results might be utilizing the TBARS assay; which, despite its popularity, lacks sensitivity and specificity [8]. Free MDA, analyzed via high performance liquid chromatography (HPLC), is a better biomarker as it can address such issues. The present study utilized VC and MDA for EIOS assessment.

The aim of the present study was to investigate if VCS would improve PMF by reducing EIOS in persons naive to RE and VCS. Saliva was utilized as the biospecimen for examining the following biomarkers: VC and MDA. All methods and procedures were approved by the University of Nevada, Reno's Institutional Review Board (IRB) prior to conducting the study. Each person signed a consent form prior to participation.

\section{Methods}

Nine persons $(n=9)$ naive to RE and VCS, that is whom did not associate with either, participated in this pre-post intervention designed study; seven males and two females between the ages 22 and 34 y/o participated. No other descriptive data from participants were controlled. Participants had to be in good health to be included in the study; common colds, illnesses, smoking, kidney disorders, and iron-metabolism disorders excluded participants from the study as each can alter systemic vitamin C and salivary results [26] [27]. Participants were asked to maintain regular diet and exercise patterns throughout the duration of the study. The intervention was VCS for 28 days. One RE bout was performed pre-VCS and one was performed post-VCS; PMF measures were quantified during each RE bout.

The Biodex System 3 Isokinetic Dynamometer (Biodex) was used with the closed kinetic chain attachment (CKC) to quantify PMF via isokinetic push-pull repetitions. Three days prior to the initial start date, participants were familiarized with the Biodex. Instructions from the Biodex manual were followed for the CKC setup. Individual setup measures for each participant were taken during this familiarization, which consisted of: attachment height; seat placement; hand position; CKC tilt; shoulder angle; handle-extension travel; and handle- 
retraction travel. Neutral hand, shoulder angle, and tilt positions were used. The neutral shoulder angle for the apparatus was $25^{\circ}$. Full handle-retraction was set for the participant's elbow to create a $90^{\circ}$ angle at his/her side at the end of travel. Full handle-extension was set for the arm to fully extend at the end of travel, creating a straight arm. Height was measured for the hand to be directly in-line with the shoulder at full extension. These parameters were used for both RE bouts.

The two RE bouts for each participant were performed at the same time of day. RE bouts consisted of a warmup set of bodyweight pushups, three working sets (WS) of 10 isokinetic contracting push-pull repetitions, and one maximal effort set (ME) of five isokinetic contracting push-pull repetitions. First, participants were asked to complete as many pushups as they could while using any style. Immediately following the pushups, participants performed the WS on the Biodex at a velocity of $120^{\circ} ; 10 \mathrm{sec}$ rest periods were given between each set as this was standard. A $90 \mathrm{sec}$ rest period was given after the WS before performing the ME set; the Biodex was set at $60^{\circ}$ for the ME set. Researchers did not cheer during either RE bout. Whole saliva samples were collected before and immediately after each RE bout; samples were frozen in a $-80^{\circ}$ freezer (Revco) for storage until analyzed. The highest quantified pushing force from the ME was recorded as the ME-PMF. The highest pushing force from each of the three performed sets during WS were also averaged and recorded as the WS-PMF.

Participants consumed $250 \mathrm{mg}$ of an over-the-counter vitamin C supplement every $12 \mathrm{hrs}$ ( $500 \mathrm{mg} /$ day) for a total of 28 days. The over-the-counter supplement was $96 \%$ potent when tested against a laboratory-grade L-ascorbic acid (Sigma-Aldrich). The United States Department of Health and Human Services' (HHS) Automated Self-Administered 24-hour Dietary Recall System (ASA24) evaluated each participant's dietary vitamin C intake. Participants were asked to complete three 24-hour dietary recalls, two from days during the week and one from a Saturday or a Sunday; the three intakes were averaged and recorded.

Methods previously described [11] were used to determine VC. Briefly, vitamin C was preserved in trichloroacetic acid in the standards and saliva (saliva was preserved immediately after collection); oxidized with cupric sulfate pentahydrate to form dehydroascorbic acid; and then reacted with 2,4-dinitrophenylhydrazine prior to incubating for three hrs at $37^{\circ}$ Celsius. All solutions were then reacted with $65 \%$ sulfuric acid for $30 \mathrm{~min}$ to form bis-2,4-dinitrophenylhydrazone. Absorbances of samples and standards were read in triplicates via a microtiter plate reader (Synergy HT microplate reader from Bio Tek Instruments, Inc.) at wavelength $520 \mathrm{~nm}$.

Methods previously described were used to determine MDA [28]. Saliva was preserved in 5\% ethylenediaminetetraacetic acid (EDTA) and butylated hydroxytoluene (BHT). To free malondialdehyde from proteins, $0.05 \mathrm{~mL}$ of each saliva sample was added to $0.25 \mathrm{~mL} 0.1 \mathrm{M}$ perchloric acid $\left(\mathrm{HClO}_{4}\right)$ and $0.7 \mathrm{~mL}$ deionized water. Standards were prepared from 1,1,3,3-tetraethoxypropane (TEP). Peak heights from the standards were used to create the calibration curve via a 
Hewlett-Packard Series 1100 HPLC with the following features: C 18 reversedphase column at ambient temperature $(25 \mathrm{~cm}, 4.6 \mathrm{~mm}$ i.d.; $5-\mu \mathrm{m}$ particles); 30 $\mathrm{mM} \mathrm{KH}_{2} \mathrm{PO}_{4}$-methanol $(65+35 \mathrm{v} / \mathrm{v} \%)$ for the single mobile phase; and the flow rate set at $1.5 \mathrm{~mL} / \mathrm{min}$. Chromatograms were monitored at $254 \mathrm{~nm}$ and injection volume was $0.002 \mathrm{~mL}$. Retention time was $1.88-1.91 \mathrm{~min}$.

All data was put into Graph Pad Prism 5 for statistical analysis. A repeated samples t-test was used to analyze statistically-significant differences in PMF measures, VC, and MDA; Figure 1 represents when each measure of the study was taken. The level of significance was set at $\mathrm{p}<0.05$.

\section{Results}

Nine subjects participated in a pre-post 28-day VCS intervention study; RE bouts were performed pre- and post-VCS to quantify PMF. MS-PMF experienced a significant increase post-VCS compared to pre-VCS MS-PMF and is presented in Figure $2(\mathrm{p}=0.016)$. MS-PMF pre-VCS measures averaged 368.31 $\mathrm{m} \cdot \mathrm{kg} \cdot \mathrm{s}^{-2}\left(\mathrm{SD}=76.36 \mathrm{~m} \cdot \mathrm{kg} \cdot \mathrm{s}^{-2}\right) ;$ post-VCS measures averaged $405.50 \mathrm{~m} \cdot \mathrm{kg} \cdot \mathrm{s}^{-2}(\mathrm{SD}$ $\left.=92.75 \mathrm{~m} \cdot \mathrm{kg} \cdot \mathrm{s}^{-2}\right)$. WS-PMF experienced a significant increase post-VCS compared to pre-VCS and is presented in Figure $3(\mathrm{p}=0.026)$. Pre-VCS WS-PMF measures averaged $247.01 \mathrm{~m} \cdot \mathrm{kg} \cdot \mathrm{s}^{-2}\left(\mathrm{SD}=56.30 \mathrm{~m} \cdot \mathrm{kg} \cdot \mathrm{s}^{-2}\right)$; post-VCS measures averaged $286.82 \mathrm{~m} \cdot \mathrm{kg} \cdot \mathrm{s}^{-2}\left(\mathrm{SD}=68.91 \mathrm{~m} \cdot \mathrm{kg} \cdot \mathrm{s}^{-2}\right)$.

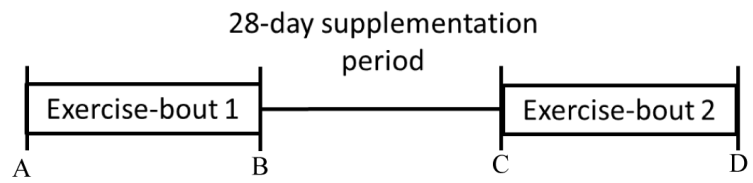

Figure 1. The study design was a pre-post intervention 28-day VCS period exercise-bouts 1 and 2 represent the RE bouts performed pre- and post-VCS. A, B, C, and D represent the time points salivary samples were taken, before and after each RE bout.

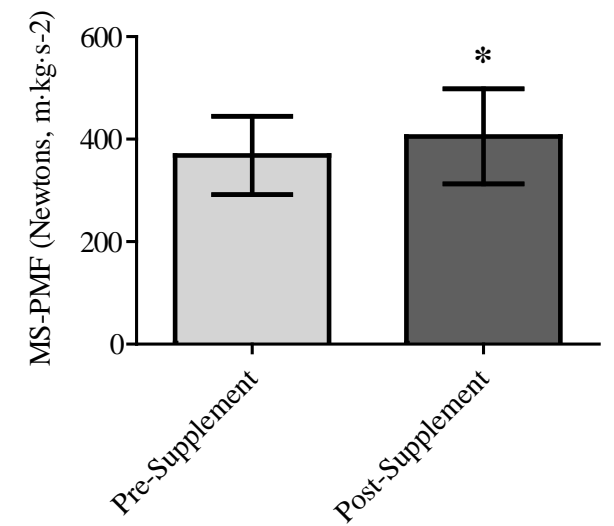

Figure 2. Peak muscular pushing force from the maximal-effort set before and after the VCS period. MS-PMP experienced a significant increase post-VCS $\left({ }^{*} \mathrm{p}<0.05\right)$. MS-PMF $=$ maximal-effort peak muscular pushing force; VCS = vitamin $\mathrm{C}$ supplementation. 


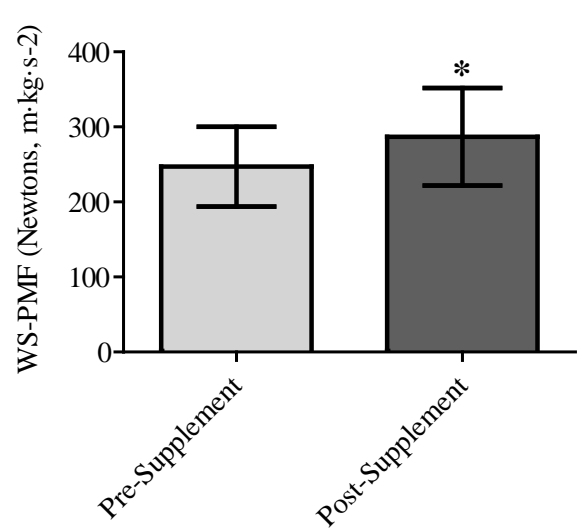

Figure 3. Peak muscular pushing force averaged from the three working sets, before and after the VCS period. WS-PMF experienced a significant increase post-VCS $\left({ }^{*} \mathrm{p}<0.05\right)$. WS-PMF $=$ average peak muscular pushing force from the three working sets; VCS = vitamin C supplementation.

MDA experienced a significant increase after each respective RE bout and is presented in Figure $4(\mathrm{p}<0.01)$. Pre-VCS and post-VCS baseline measures averaged $0.37 \mu \mathrm{g} / \mathrm{mL}(\mathrm{SD}=0.014)$ and $0.36 \mu \mathrm{g} / \mathrm{mL}(\mathrm{SD}=0.008)$, respectively; MDA averaged $0.39 \mu \mathrm{g} / \mathrm{mL}(\mathrm{SD}=0.017)$ pre-VCS and $0.37 \mu \mathrm{g} / \mathrm{mL}(\mathrm{SD}=0.014)$ post-VCS after each respective RE bout. MDA experienced a significant decrease post-VCS; this was observed before and after the post-VCS RE bout $(\mathrm{p}=0.01 ; \mathrm{p}$ $=0.03)$ as well as overall $(\mathrm{p}=0.0007)$.

VC experienced a significant increase post-VCS compared to pre-VCS and is presented in Figure $5(\mathrm{p}<0.0001)$. Pre-VCS measures averaged $0.47 \mu \mathrm{g} / \mathrm{mL}$ (SD $=0.51 \mu \mathrm{g} / \mathrm{mL}) ;$ post-VCS measures averaged $1.22 \mu \mathrm{g} / \mathrm{mL}(\mathrm{SD}=0.73)$. The average dietary vitamin $\mathrm{C}$ intake amongst the participants was $76 \mathrm{mg} /$ day, with the highest being $257 \mathrm{mg} /$ day and the lowest being $18 \mathrm{mg} /$ day. No significant differences in PMF measures were calculated amongst the participants in relation to dietary vitamin $\mathrm{C}$ intakes.

\section{Discussion}

This study reports that VCS of $250 \mathrm{mg}$ every $12 \mathrm{hrs}$ for 28 days can reduce oxidative stress and increase muscular force in persons whom were naive to RE and VCS. VCS can also substantially increase systemic vitamin C as observed via VC. The elevation of MDA after each RE bout suggests that oxidative stress was induced. MDA measures taken post-VCS decreased; this was observed before and after the respective RE bout, as well as overall, suggesting EIOS reduction. Plasma MDA after acute exercise has previously been reduced post-VCS [29]; this study confirms VCS's ability to reduce EIOS at $500 \mathrm{mg} /$ day. The increased MS-PMF and WS-PMF post-VCS suggests reducing oxidative stress can affect muscular force positively in the involved population.

Few researchers have studied vitamin $\mathrm{C}$ in resistance/anaerobic exercise. The Biodex with the CKC attachment at $60^{\circ}$ and $120^{\circ}$ speeds was utilized in this 


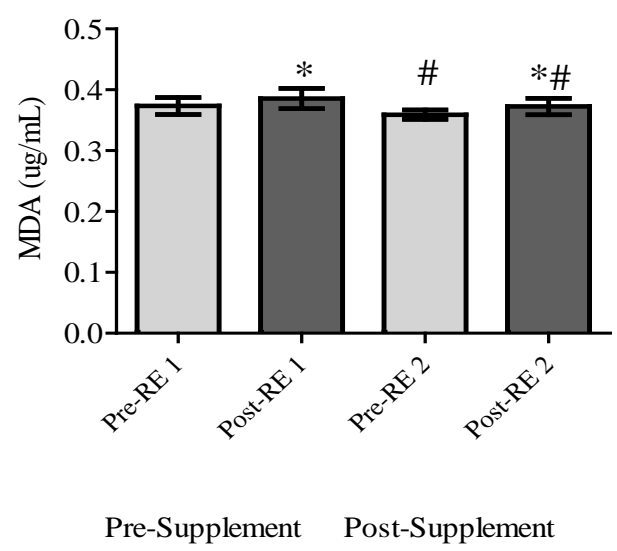

Figure 4. Free salivary malondialdehyde measures from the four separate saliva collections. MDA experienced significant increases after both RE bouts $\left({ }^{*} p<0.01\right)$. Significant reductions were experienced post-VCS compared to the same time points pre-VCS (\#p $<0.01) . \mathrm{MDA}=$ free salivary malondialdehyde; $\mathrm{RE}=$ resistance exercise; VCS = vitamin C supplementation.

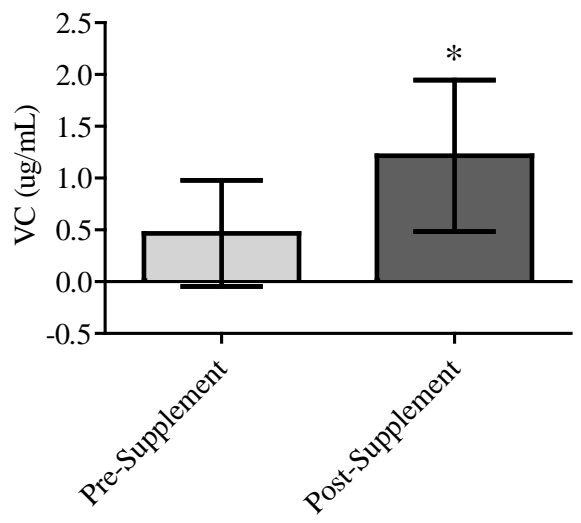

Figure 5. Salivary vitamin $C$ pre- and post-vitamin $C$ supplementation for 28 days. VC experienced a significant increase post-VCS compared to pre-VCS $\left({ }^{*} \mathrm{p}<0.0001\right)$. VC $=$ salivary vitamin $\mathrm{C}$; VCS $=$ vitamin $\mathrm{C}$ supplementation.

study; methods and speeds have previously been researched in test-retest environments (pre-post studies without intervention) with no significant changes in PMF [30] [31]. The increases in PMF suggest the VCS intervention as the major contributing factor. VCS at doses (400 mg/day) similar to this study's dose (500 $\mathrm{mg}$ /day) have also been able to demonstrate a positive effect on muscular force/ function via dynamometry [18] [32]. Higher doses ( $1 \mathrm{~g} /$ day, $3 \mathrm{~g} /$ day), however, have had a negative effect or no effect at all on muscular force/function [17] [22]. In these respective studies, results of RE-induced muscle soreness differed as one was not reduced while the other was. The exercises also differed; both differed from this study's RE bouts, however, as muscle soreness was not examined. Other resistance/anaerobic exercise studies have observed no effect on RE-induced muscle soreness after VCS at low and high doses [33] [34] suggesting dose 
might not contribute to the outcome.

Force produced by the muscle, specifically the myofilament portion, is heavily influenced by sarcoplasmic reticulum $\mathrm{Ca}^{2+}$. Reactive/nonreactive species can diminish myofilaments' sensitivity to $\mathrm{Ca}^{2+}$ or can cause $\mathrm{Ca}^{2+}$ to leak and not attach during the muscle contraction process, which will ultimately reduce muscular force [35]. This might be due to reactive species' ability to nitrosylate ryanodine receptor 1 proteins (RyR1) [36]. Vitamin C has been shown to denitrosylate the sarcoplasmic reticulum RyR1 proteins that are S-nitrosylated [37]; it has also been shown to attenuate S-nitrosylation [38]. RyR1 proteins are more so affected by hydrogen peroxide, a compound that does not necessarily react physiologically with vitamin C [39]. It could be possible; however, that vitamin C indirectly reacts with hydrogen peroxide products to which could affect such redox sensitive pathways.

This study did not have a control group, which should be included in future studies. A study with a group supplementing $3 \mathrm{~g}$ of vitamin $\mathrm{C}$ for 14 days observed no difference in muscle function compared to a control group [17]; 70 eccentric contractions were performed as the exercise to induce oxidative stress. This study and the current study used untrained persons. It is possible that the exercise performed previously was more damaging as this study had subjects perform a total of 30 concentric contractions; eccentric contractions might be more damaging. Future studies should consider different intensity levels with a lower VCS dose, as doses less than and equal to $500 \mathrm{mg} /$ day tend to have positive results. RE experience should also be controlled. Furthermore, the muscle contraction pathway (sarcoplasmic reticulum and RyR1) should be further examined with VCS.

In conclusion, this study reports that $250 \mathrm{mg}$ of VCS every $12 \mathrm{hrs}$ for 28 days reduced EIOS in conjunction with increased muscular force in persons naïve to RE and VCS. No other RE bouts were performed during the VCS intervention. The salivary biomarkers, MDA and VC, were influenced in a way that has previously been witnessed in plasma, the biospecimen more often used in research. VCS increased VC and reduced MDA. VCS was set at a dose known to limit excretion and was supplemented in persons thought to experience more detrimental effects in regards to EIOS. Results suggest VCS could be potentially useful in $\mathrm{RE}$ for individuals beginning to weight train and take vitamin $\mathrm{C}$ supplements.

\section{Acknowledgements}

Levi W. Evans and Stanley T. Omaye contributed equally to the research conducted and to the writing of this manuscript. Fan Zhang helped perform the HPLC experiments.

\section{References}

[1] Nordberg, J. and Arner, E. (2001) Reactive Oxygen Species, Antioxidants, and the Mammalian Thioredoxin System. Free Radical Biology \& Medicine, 31, 1287-1312. 
https://doi.org/10.1016/S0891-5849(01)00724-9

[2] Deminice, R., Sicchieri, T., Payão, P. and Jordão, A. (2010) Blood and Salivary Oxidative Stress Biomarkers Following an Acute Session of Resistance Exercise in Humans. International Journal of Sports Medicine, 31, 599-603. https://doi.org/10.1055/s-0030-1255107

[3] Lee, J., Goldfarb, A., Rescino, M., Hegde, S., Patrick, S. and Apperson, K. (2002) Eccentric Exercise Effect on Blood Oxidative-stress Markers and Delayed Onset Muscle Soreness. Medicine and Science in Sports and Exercise, 34, 443-448. https://doi.org/10.1097/00005768-200203000-00010

[4] Alessio, H., Goldfarb, A. and Cutler, R. (1988) MDA Content Increases in Fast- and Slow-Twitch Skeletal Muscle with Intensity of Exercise in a Rat. American Journal of Physiology, 255, C874-C877.

[5] Davies, K., Quintanilha, A., Brooks, G. and Packer, L. (1982) Free Radicals and Tissue Damage Produced by Exercise. Biochemical and Biophysical Research Communications, 107, 1198-1205. https://doi.org/10.1016/S0006-291X(82)80124-1

[6] Reid, M. (2001) Invited Review: Redox Modulation of Skeletal Muscle Contraction: What We Know and What We Don't. Journal of Applied Physiology, 90, 724-731.

[7] Moopanar, T. and Allen, D. (2005) Reactive Oxygen Species Reduce Myofibrillar $\mathrm{Ca}(2+)$ Sensitivity in Fatiguing Mouse Skeletal Muscle at 37 Degrees Celsius. Journal of Physiology, 564, 189-199. https://doi.org/10.1113/jphysiol.2005.083519

[8] Halliwell, B. and Getteridge, J. (2007) Free Radicals in Biology and Medicine, $4^{\text {th }}$ Edition, Oxford University Press, Oxford.

[9] Steinbacher, P. and Eckl, P. (2015) Impact of Oxidative Stress on Exercising Skeletal Muscle. Biomolecules, 5, 356-377. https://doi.org/10.3390/biom5020356

[10] Higdon, J. and Frei, B. (2002) Vitamin C: An Introduction. In: Packer, L., Ed., The Antioxidant Vitamins C and E, AOCS Press, Santa Barbara, 8-24.

[11] Omaye, S., Turnbull, J. and Sauberlich, H. (1979) Selected Methods of the Determination of Ascorbic Acid in Animal Cells, Tissues, and Fluids. Methods of Enzymol$o g y, 62,3-11$.

[12] Padayatty, S., Sun, H., Wang, Y., Riordan, H., Hewitt, S.K., Wesley, R. and Levine, M. (2004) Vitamin C Pharmacokinetics: Implications for Oral and Intravenous Use. Annals of Internal Medicine, 140, 533-537. https://doi.org/10.7326/0003-4819-140-7-200404060-00010

[13] Rock, C., Newman, V., Neuhouser, M., Major, J. and Barnett, M. (2004) Antioxidant Supplement Use in Cancer Survivors and the General Population. The Journal of Nutrition, 134, 3194S-3195S.

[14] Braun, H., Koehler, K., Geyer, H., Kleiner, J., Mester, J. and Schanzer, W. (2009) Dietary Supplement Use among Elite Young German Athletes. International Journal of Sport Nutrition and Exercise Metabolism, 19, 97-109. https://doi.org/10.1123/ijsnem.19.1.97

[15] Sieburg, H. (1937) Redoxon as a Tonic for Sportsmen. Deutsche Medizinische Wochenschrift, 63, 11-12.

[16] Jetzler, A. and Haffler, C. (1939) Vitamin C-Bedarf Bei Einmaligar Sportlicher Dauerleistung. Wiener Medizinische Wochenschrift, 89, 332.

[17] Bryer, S. and Goldfarb, A. (2006) Effect of High Dose Vitamin C Supplementation on Muscle Soreness, Damage, Function, and Oxidative Stress to Eccentric Exercise. International Journal of Sport Nutrition and Exercise Metabolism, 16, 270-280. https://doi.org/10.1123/ijsnem.16.3.270 
[18] Thompson, D., Williams, C., McGregor, S., Nicholas, C., McArdle, F., Jackson, M. and Powell, J. (2001) Prolonged Vitamin C Supplementation and Recovery from Demanding Exercise. International Journal of Sport Nutrition and Exercise Metabolism, 11, 466-481. https://doi.org/10.1123/ijsnem.11.4.466

[19] Sharifi, G., Mazreno, A., Jalili, F., Salmani, I. and Mazraeno, E. (2014) Effect of Supplemental Ascorbic Acid on the Aerobic Capacity in Children. International Journal of Pediatrics, 2, 239-243.

[20] Gomez-Cabrera, M., Domenech, E., Romagnoli, M., Arduini, A., Borras, C., Pallardo, F. and Via, J. (2008) Oral Administration of Vitamin C Decreases Muscle Mitochondrial Biogenesis and Hampers Training-Induced Adaptations in Endurance Performance. The American Journal of Clinical Nutrition, 87, 142-149.

[21] Roberts, L., Beattie, K., Close, G. and Morton, J. (2011) Vitamin C Consumption Does Not Impair Training-Induced Improvements in Exercise Performance. International Journal of Sports Physiology and Performance, 6, 58-69.

https://doi.org/10.1123/ijspp.6.1.58

[22] Close, G., Ashton, T., Cable, T., Doran, D., Holloway, C., McArdle, F. and MacLaren, D. (2006) Ascorbic Acid Supplementation Does Not Attenuate Post-Exercise Muscle Soreness Following Muscle-Damaging Exercise but May Delay the Recovery Process. British Journal of Nutrition, 95, 976-981. https://doi.org/10.1079/BJN20061732

[23] McArdle, W., Katch, F. and Katch, V. (2007) Exercise Physiology: Energy, Nutrition and Human Performance. 6th Edition, Williams \& Williams, Maryland.

[24] Evans, L. and Omaye, S. (2017) Use of Saliva Biomarkers to Monitor Efficacy of Vitamin C in Exercise-Induced Oxidative Stress. Antioxidants, 6, 5. https://doi.org/10.3390/antiox6010005

[25] Sant'anna, M., Casimiro-Lopes, G., Boaventura, G., Marques, S., Sorenson, M., Simão, R. and Pinto, V. (2016) Anaerobic Exercise Affects the Saliva Antioxidant/oxidant Balance in High-Performance Pentathlon Athletes. Human Movement, 17, 50-55.

[26] Gropper, S., Smith, J. and Groff, J. (2013) Advanced Nutrition and Human Metabolism. 6th Edition, Wadsworth, Cengage Learning, Belmont.

[27] Dugue, B., Ilardo, C., Aimone-Gastin, I., Gueant, J., Mouze-Amady, M., Cnockaert, J., Grasbeck, R., et al. (1999) Cytokines in Saliva. Basal Concentrations and the Effect of High Ambient Heat (Sauna). Stress Medicine, 12, 193-197. https://doi.org/10.1002/(SICI)1099-1700(199607)12:3<193::AID-SMI701>3.0.CO;2Z

[28] Karatas, F., Karatepe, M. and Baysar, A. (2002) Determination of Free Malondialdehyde in Human Serum by High-Performance Liquid Chromatography. Analytical Biochemistry, 311, 76-79.

[29] Popovic, L., Mitic, N., Miric, D., Bisevac, B., Miric, M. and Popovic, B. (2015) Influence of Vitamin C Supplementation on Oxidative Stress and Neutrophil Inflammatory Response in Acute and Regular Exercise. Oxidative Medicine and Cellular Longevity, 2015, Article ID: 295497. https://doi.org/10.1155/2015/295497

[30] Cools, A., Witvrouw, E., Danneels, L., Vanderstraeten, G. and Cambier, D. (2002) Test-Retest Reproducibility of Concentric Strength Values for Shoulder Girlder Protraction and Retraction Using the Biodex Isokinetic Dynamometer. Isokinetics and Exercise Science, 10, 129-136.

[31] Riemann, B., Davis, S., Huet, K. and Davies, G. (2016) Intersession Reliability of Upper Extremity Isokinetic Push-pull Testing. The International Journal of Sports 
Physical Therapy, 11, 85.

[32] Jakeman, P. and Maxwell, S. (1993) Effect of Antioxidant Vitamin Supplementation on Muscle Function after Eccentric Exercise. European Journal of Applied Physiology and Occupational Physiology, 67, 426-430. https://doi.org/10.1007/BF00376459

[33] Connoly, D., Lauzon, C., Agnew, J., Dunn, M. and Reed, B. (2006) The Effects of Vitamin C Supplementation on Symptoms of Delayed Onset Muscle Soreness. The Journal of Sports Medicine and Physical Performance, 46, 462-467.

[34] Thompson, D., Bailey, D., Hill, J., Hurst, T., Powell, J. and Williams, C. (2004) Prolonged Vitamin C Supplementation and Recovery from Eccentric Exercise. European Journal of Applied Physiology, 92, 133-138. https://doi.org/10.1007/s00421-004-1064-y

[35] Powers, S. and Jackson, M. (2008) Exercise-induced Oxidative Stress: Cellular Mechanisms and Impact on Muscle Force Production. Physiological Reviews, 88, 1243-1276. https://doi.org/10.1152/physrev.00031.2007

[36] Sun, Q., Hess, D.L.N., Yong, S., Bowles, D. and Eu, J.S. (2011) Oxygen-Coupled Redox Regulation of the Skeletal Muscle Ryanodine Receptor Calcium Ion Release Channel by NADPH Oxidase 4. Proceedings of the National Academy of Sciences of the USA, 108, 16098-16103. https://doi.org/10.1073/pnas.1109546108

[37] Holmes, A. and Williams, D. (2000) Reaction of Ascorbic Acid with S-Nitrosothiols: Clear Evidence for Two Distinct Reaction Pathways. Journal of the Chemical Society Perkin Transactions, 2, 1639-1644. https://doi.org/10.1039/b004028m

[38] Dutka, T., Mollica, J. and Lamb, G. (2011) Differential Effects of Peroxynitrite on Contractile Protein Properties in Fast- and Slow-Twitch Skeletal Muscle Fibers of Rat. Journal of Applied Physiology, 110, 705-716. https://doi.org/10.1152/japplphysiol.00739.2010

[39] Cobley, J., McHardy, H., Morton, J., Nikolaidis, M. and Close, G. (2015) Influence of Vitamin C and Vitamin E on Redox Signaling: Implications for Exercise Adaptations. Free Radical Biology \& Medicine, 84, 65-76.

Scientific Research Publishing

Submit or recommend next manuscript to SCIRP and we will provide best service for you:

Accepting pre-submission inquiries through Email, Facebook, LinkedIn, Twitter, etc. A wide selection of journals (inclusive of 9 subjects, more than 200 journals)

Providing 24-hour high-quality service

User-friendly online submission system

Fair and swift peer-review system

Efficient typesetting and proofreading procedure

Display of the result of downloads and visits, as well as the number of cited articles

Maximum dissemination of your research work

Submit your manuscript at: http://papersubmission.scirp.org/

Or contact fns@scirp.org 